\title{
I dentification of patients with defects in the globin genes by analysing blood parameters and genetic study: Report of five cases
}

\author{
Domenico Dell'Edera ${ }^{1}$, Michele Benedetto ${ }^{1}$, Manuela Leo ${ }^{1}$, Carmela Santacesaria ${ }^{1}$, Arianna \\ Allegretti $^{1}$, Maria Giovanna Lupo ${ }^{1}$, Eleonora Mazzone ${ }^{1}$, Annunziata Anna Epifania ${ }^{2}$ \\ 1. Unit of Cytogenetic and Molecular Genetics, “Madonna delle Grazie” Hospital, Matera, Italy. 2. Unit of Clinical \\ Chermistry, "Madonna delle Grazie" Hospital, Matera, I taly.
}

Correspondence: Domenico Dell'Edera. Address: Unit of cytogenetic and molecular genetics Hospital "Madonna delle Grazie"-75100 Matera, Italy. Email: domenicodelledera68@gmail.com

Received: December 12, 2013

Accepted: January 5, 2014

DOI : $10.5430 / j h m . v 3 n 2 p 29$

URL: http://dx.doi.org/10.5430/jhm.v3n2p29

Online Published: January 6, 2014

\section{Abstract}

Hemoglobinopathies constitute a major health problem worldwide, with a high carrier frequency, particularly in certain regions where malaria has been endemic. These disorders are characterized by a vast clinical and hematological phenotypic heterogeneity. The laboratory investigation includes determination of RBC indices, hemoglobin pattern, serum ferritin, quantification of $\mathrm{HbA} 2, \mathrm{HbF}$ and detection of $\mathrm{Hb}$ variants by $\mathrm{HPLC}$ (High performance liquid chromatography). Furthermore, in order to accurately identify thalassemia through molecular identification of globin gene, useful insights are provided by family studies and comprehensive hematological analyses.

We have analyzed five cases with borderline hematological parameters. Four of these five cases involve pregnant women that have come to our observation to undergo first trimester combined test. Due to the uncertainty of the biochemical and hematological parameters, it was necessary to evaluate the globin genes to detect mutations causing haematological borderline values.

The aim of this paper is to highlight that the biochemical diagnosis alone, in some cases, is not sufficiently reliable to highlight the carriers of thalassemia trait.

The evidence suggests that the molecular analysis of globin genes provides the most effective way to correctly detect carriers of thalassemia trait. The detected mutations in this work can be identified with a simple and inexpensive kit. This would generate, in economic terms, significant savings.

\section{Key words}

$\alpha$ thalassemia, $\beta$ thalassemia, $\mathrm{HbA} 2$ levels, Carriers screening, Prenatal diagnosis

\section{I ntroduction}

Thalassemias are a group of blood genetic disorders, inherited in autosomal recessive manner. Defects in these genes can produce abnormal hemoglobin and anemia. Abnormal hemoglobin appears in one of three basic conditions: structural 
defects in the hemoglobin molecule, diminished production of one of the two subunits of the hemoglobin molecule (thalassemias), and abnormal association of otherwise normal subunits ${ }^{[1]}$.

Occasionally, someone inherits two different variants from the alpha globin gene cluster or two different variants from beta globin gene cluster. This condition is called compound heterozygosity. The nature of the two inherited genes determines whether a clinically significant disease state develops. Among these, the thalassemias include a diverse group of disorders and are broadly classified into $\alpha, \beta, \delta \beta$ and $\gamma \delta \beta$ thalassemias, depending on the globin chain(s), which are insufficiently synthesized ${ }^{[2,3]}$.

Some biochemical tests ( $\mathrm{Hb}, \mathrm{HbF}, \mathrm{HbA} 2, \mathrm{RBC}, \mathrm{MCV}, \mathrm{MCH})$ are useful for identifying carriers of the thalassemia trait ${ }^{[4]}$. In the presence of thalassemic parameters in the $\mathrm{CBC}$, an accurate and precise quantification of hemoglobin $\mathrm{HbA} 2$ is essential for the diagnosis of the thalassemia trait. When biochemical tests are not exhaustive, it is necessary to study the molecular globin genes ${ }^{[5-7]}$.

\section{Case reports}

This work has the objective to characterize, in the most accurate possible way, five cases where the molecular investigation was necessary to highlight the carriers of globin disorders.

\section{Materials and methods}

\subsection{Patients}

For the purposes of this paper, we have analyzed 5 cases: a child and four pregnant women. The first one was a five-years old patient who underwent the screening for anemia. The initial results of his biochemical and hematological test had led to the hypothesis that the child was a carrier of thalassemic trait (see Table 1).

Table 1. Biochemical parameters

\begin{tabular}{|c|c|c|c|c|c|c|c|c|c|c|}
\hline & \multirow{2}{*}{$\begin{array}{l}\text { Normal Range } \\
\text { Values }\end{array}$} & \multirow{2}{*}{$1^{\text {st }}$ case } & \multicolumn{2}{|c|}{$2^{\text {nd }}$ case } & \multicolumn{2}{|c|}{$3^{\text {rd }}$ case } & \multicolumn{2}{|c|}{$4^{\text {th }}$ case } & \multicolumn{2}{|l|}{$5^{\text {th }}$ case } \\
\hline & & & wife & Husband & wife & husband & wife & husband & Wife & husband \\
\hline $\mathrm{RBC}\left(10^{\wedge} 6 / \mu \mathrm{L}\right)$ & $4.00-5.10$ & 4.75 & $5.33 \uparrow$ & $5.69 \uparrow$ & $5.92 \uparrow$ & $5.33 \uparrow$ & $5.11 \uparrow$ & $6.58 \uparrow$ & $5.2 \uparrow$ & $5.69 \uparrow$ \\
\hline $\mathrm{Hb}(\mathrm{g} / \mathrm{dL})$ & $11.8-15.1$ & $9.2 \downarrow$ & $11.4 \downarrow$ & $16.7 \uparrow$ & 12.4 & $11.4 \downarrow$ & 12.8 & 13.0 & $11.2 \downarrow$ & 12.9 \\
\hline MCV (fl) & $80-98$ & $60.6 \downarrow$ & $67.9 \downarrow$ & 85.2 & $63 \downarrow$ & $62.9 \downarrow$ & $79.8 \downarrow$ & $58.8 \downarrow$ & $65.2 \downarrow$ & $68.7 \downarrow$ \\
\hline $\mathrm{MCH}$ (pg) & $27.0-32.0$ & $19.4 \downarrow$ & $21.5 \downarrow$ & 29.3 & 30 & $21.4 \downarrow$ & 27.2 & $19.8 \downarrow$ & $21.5 \downarrow$ & $22.7 \downarrow$ \\
\hline $\mathrm{HbF}(\%)$ & $<1.0$ & $9.3 \uparrow \uparrow$ & $1.5 \uparrow$ & 0.5 & $1.5 \uparrow$ & 1.0 & 0.6 & 0.4 & $11.3 \uparrow \uparrow$ & 0.6 \\
\hline $\mathrm{HbA} 2(\%)$ & $<3.2$ & 1.3 & $4.4 \uparrow$ & $3.6 \uparrow$ & $4.4 \uparrow$ & 2.7 & 2.9 & 1.9 & 2.7 & $3.7 \uparrow$ \\
\hline
\end{tabular}

The second case was about a couple: a 30-years-old pregnant woman (first pregnancy) and his husband. The woman was admitted to our Unit at 12 weeks for a screening for thalassemia. The outcomes of the biochemical and hematological exams (see Table 1) highlighted that the patient was a carrier of a beta thalassemic trait. The biochemical and hematological parameters of her husband (see Table 1) were normal, except for the level of $\mathrm{HbA} 2(3.6 \%)$.

The third patient was a 29 -years-old pregnant. She was admitted to our Unit and the first trimester combined test was performed at 11 weeks of gestation. The final risk for trisomy 21 was equal to 1:1000. Before carrying out the tests we carefully compiled the medical history of both the patient and her husband. The outcomes of the biochemical and hematological exams (see Table 1) highlighted that the woman under observation was a carrier of the beta-thalassemic trait. 
The fourth case was about a 33-years-old pregnant woman and her husband. She was admitted to our Unit and the first trimester combined test was performed at 12 weeks of gestation. The final risk for trisomy 21 was equal to 1:950. This patient presented biochemical parameters associated with thalassemia trait (see Table 1). Instead, her husband had biochemical elements associated to $\alpha$-thalassemic trait (see Table 1).

The fifth patient was a 26-years-old pregnant. She was admitted to our Unit and the first trimester combined test was performed at 12 weeks of gestation. The final risk for trisomy 21 was equal to 1:1850. The pregnant woman presented a high $\mathrm{HbF}(11.3 \%)$ with hematological parameters associated with beta thalassemia trait (see Table 1). Furthermore, even some hematological parameters of the patient's husband were not in the prefixed range (see Table 1).

\subsection{Biochemical and hematological parameters}

In each of the five cases, the following tests were applied after venous blood samples were obtained from all subjects (collected in tubes containing EDTA-K3):

- Blood films for erythrocytes morphology.

- Detection of red cell indices with Sysmex XE 2100 automated cell counter (Dasit Cornaredo, Milan, Italy): red blood cells count (RBC), hemoglobin $(\mathrm{Hb})$, mean corpuscular volume (MCV), mean corpuscular hemoglobin levels $(\mathrm{MCH})$, mean corpuscular hemoglobin concentration (MCHC).

- High performance liquid chromatography (HPLC) to quantify hemoglobin subtypes in the blood samples through Tosoh HPLC G7 system (Tosoh Bioscience S.r.l. - Turin, Italy) ${ }^{[8]}$.

- Assays of serum iron and serum ferritin through monitoring of their levels by Elecsys 2010 (Roche Diagnostics $\mathrm{GmbH})$.

\subsection{Genomic DNA preparation}

The molecular analysis of the globin genes was performed following the DNA isolation, starting from $25 \mu \mathrm{l}$ of blood, using the extraction kit of Promega Italy S.r.l. (DNA IQTM System, cod.C6701).

\subsection{Study of the globin genes}

- The polymerase chain reaction (PCR) and reverse-hybridization was performed. The procedure includes two steps: PCR amplification using biotinylated primers and hybridization of amplification products to a test strip containing allele-specific oligonucleotide probes immobilized as an array of parallel lines. Bound biotinylated sequences are detected using streptavidin-alkaline phosphatase and color substrates. The amplification and the reverse hybridization on a strip were obtained with the use of commercial kits produced by Nuclear Laser Medicine. The genetic tests were aimed at checking 25 mutations in the $\beta$-globin genes and 21 mutations in the $\alpha$-globin genes. The analysed mutations are listed in Figures 1 and 2.

Additional molecular studies have been carried for the cases where the molecular analysis did not reveal the status of the patients:

- Amplification, followed by enzymatic digestion for the research of the mutation $\delta^{+}$cod. $27 \mathrm{G}>\mathrm{T}$ ) (replacement of a single base of the codon no. 27, first exon of the $\delta$ gene). The restriction enzyme used was the HaeIII (BioLabs, London, and New England). The resulting product was subjected to electrophoresis on agarose gel (3\%) in TAE $1 \mathrm{X}$ buffer and subsequent ethidium bromide staining.

- Gap-PCR was used to detect a particular form of $\beta$-thalassemia, the Sicilian $\delta \beta$ thalassemia. Three primers were used for the analysis of mutations: 
- F1: 5'-TTGGGTTTCTGATAGGCACTG-3';

- F2: 5'-GTGTCACCCATTAATGCCTTGTAC-3';

- F3: 5'-TAGATCCCTTTGCCATTATG-3'.

The resulting product was subjected to electrophoresis on agarose gel (1.2\%) containing ethidium bromide in TAE 1X. The size of the fragments obtained after amplification for the mutations were:

- 1585 bp (Normal homozygous);

- $1585+1150 \mathrm{bp}$ (Heterozygote).

\section{Results}

In the first case (5-years-old patient), given the particular biochemical profile (see Table 1) it was necessary to study the molecular alpha and beta globin genes. The molecular analysis of the beta globin genes highlighted a $\beta^{+}$IVS1.1G $>A$ heterozygous mutation (see Figure 1). The molecular analysis of the alfa globin genes highlighted an anti $3.7 \mathrm{~Kb}$ gene triplication heterozygous mutation (see Figure 2). Carriers of this mutation show no clinical symptoms or hematological changes, although a considerable amount of literature has reported that the existence of this mutation with mutations in $\beta$ globin genes worsens the clinical characteristics of the patient, as it has been found in this case ${ }^{[9]}$.

Figure 1. List of mutations researched in the beta globin genes and mutations detected in the five cases studied

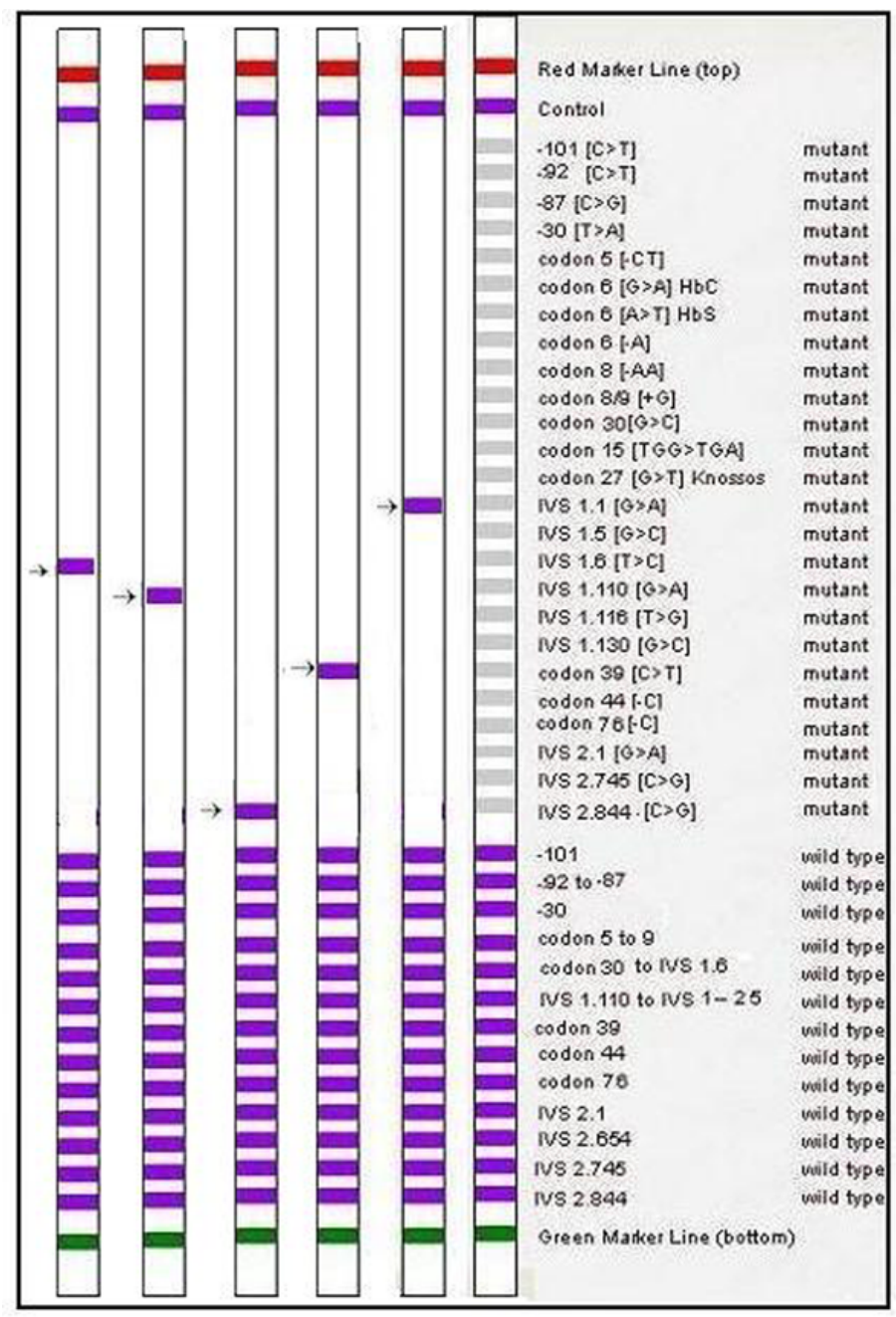


Figure 2. List of mutations researched in the alpha globin genes and mutations detected in the five cases studied

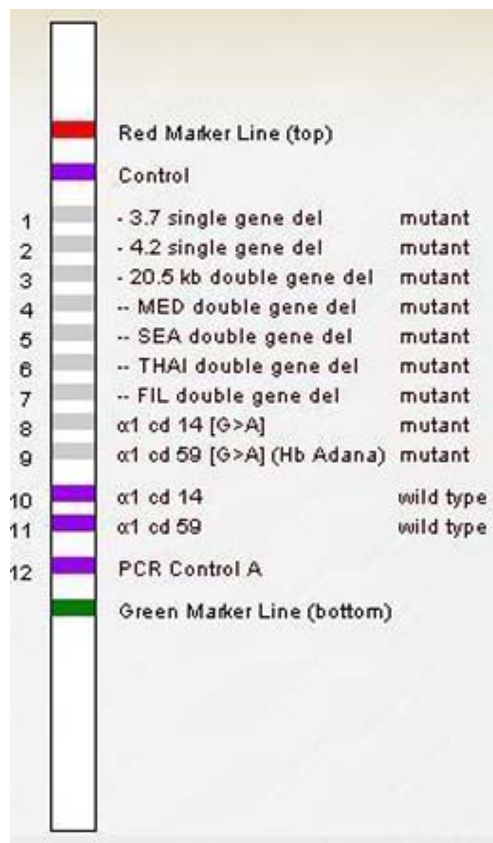

In the second case the molecular analysis of the beta globin genes highlighted a $\beta^{0} 39 \mathrm{C}>\mathrm{T}$ heterozygous mutation (see Figure 1). The biochemical and hematological parameters of the partner (see Table 1) were normal, except for the level of $\mathrm{HbA} 2(3.6 \%)$. Molecular analysis of the beta globin genes showed the mutation IVS2nt844C $>\mathrm{G}$ (heterozygous) (see Figure 1). Furthermore, the heterozygous mutation $\delta^{+} \operatorname{cod} .27 \mathrm{G}>\mathrm{T}$ was detected in the $\delta$ globin gene of the partner. For this reason, he was diagnosed with a $\delta+\beta$ thalassemia (see Figure 3 ).

Our case showed that when a member of the couple is found having a thalassemic trait and his/her partner is found to be a carrier of $\delta+\beta$ thalassemia, the couple should be informed about the possibility of conceiving a child with non-transfusion-dependent thalassemia. Our purpose is to identify at-risk couples and offer them comprehensive and accurate information on the clinical implications of the genetic defect.

In the third case the husband's biochemical and hematological parameters (see Table 1) were difficult to assess: the regularity of $\mathrm{HbA} 2(2.7 \%)$ was in contrast with the value of the MCV (62.9 fl) and $\mathrm{MCH}(21.4 \mathrm{pg})$. Performing further molecular investigation we were able to characterize the molecular state of the partners' globin genes: we found $\beta^{+}$IVS1.110G $>$A mutation in heterozygosis in the wife's $\beta$ globin genes (according with the hematological's results) and the $\beta^{0} 39 \mathrm{C}>\mathrm{T}$ mutation in heterozygosis in the husband's $\beta$-globin genes (see Figure 1). We informed the couple about the risk of conceiving a child affected by $\beta$-thalassemia (25\%). In agreement with the couple it was decided to carry out a prenatal diagnosis through chorionic villus sampling. Following the results of the molecular analysis we were able to correctly inform the couple about their clinical situation.

The fourth case pregnant woman presents biochemical parameters associated with thalassemia trait (see Table 1), instead her husband had a biochemical associated to $\alpha 1$-TAL (see Table 1). The molecular analysis showed with certainty that the woman carried $\alpha_{2}$ init $\mathrm{Cd}(\mathrm{T}>\mathrm{C}) \mathrm{NcoI}$ mutation ( $\alpha_{2}$-TAL genotype), her husband had genotype $\alpha^{0}-20.5 \mathrm{~Kb}$ double deleted gene, confirming $\alpha_{1}$-TAL phenotype. 
Figure 3. mutation research $\delta+\operatorname{cod} .27 \mathrm{G}>\mathrm{T}$ electrophoretic trace obtained after amplification annd digestion with enzyme HealII. In the presence of the mutation HeallI enzyme cuts the fragment amplified in three pieces. In the absence of mutation the enzyme cuts the fragment in two pieces

Lanes 1 and 2: amplified DNA and digested subject known for not having the mutation in the $\delta$ gene (presence of two electrophoretic bands)

Lane 3: amplified DNA and digested of husband second case. present in heterozygosity mutation $\delta+\operatorname{cod} .27 \mathrm{G}>\mathrm{T}$ (presence of three electrophoretic bands)
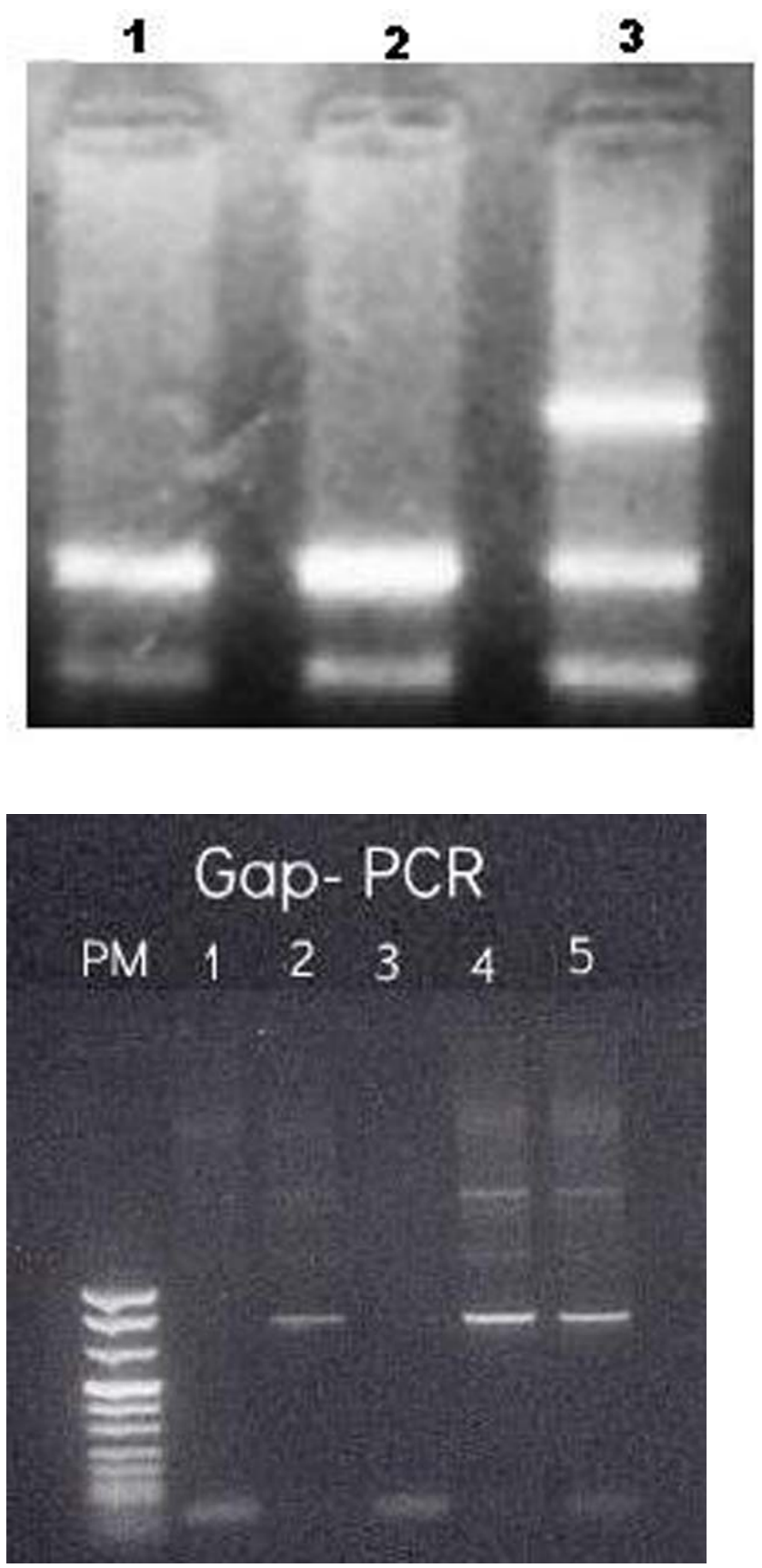

Figure 4. Gap-PCR. lane 1, 3: normal subjects. lane 2, 4,5 heterozygous Sicilian $\delta \beta$-thalassemia

Since one spouse is affected by $\alpha_{2}$-TAL and the other one is affected by $\alpha_{1}$-TAL, we informed the couple about the probability to conceive a child affected by $\mathrm{HbH}$.

We believe about the primary importance of performing a molecular analysis on the globin genes when the biochemical and hematological parameters are not clarified, like in the current case. Through the molecular analysis, in effect, it was possible to clarify the molecular state of the partners' globin genes.

In the fifth case the pregnant woman presents a high $\mathrm{HbF}(11.3 \%)$ with red cell parameters associated with beta thalassemia trait (see Table 1). The molecular analysis did not show any mutation in $\alpha$ and $\beta$ globin genes. As a consequence, it was necessary to perform other analysis in order to detect the cause of the altered hematological values. Through the Gap-PCR (see Figure 4) we were able to identify a deletion, in heterozygosis, caused by an unequal crossing 
over between $\delta$ and $\beta$ globin genes called Sicilian $\delta \beta$-thalassemia. $\delta \beta$-thalassemia is characterized by the occurrence of large deletions involving the $\delta$ and $\beta$ globin genes ${ }^{[10]}$. Heterozygous carriers of $\delta \beta$-thalassemia show HbF levels ranging from $4.0 \%$ to $18.6 \%{ }^{[1,12]}$. Furthermore, even some hematological parameters of the patient's partner were not in the prefixed range (see Table 1). The molecular analysis of the beta globin genes highlighted an IVS1.6T $>$ C heterozygous mutation (see Figure 1). We informed the couple about the risk to have a child compound heterozygote for "Sicilian $\delta \beta$-thalassemia/IVS1.6T $>$ C" $(25 \%)$. In this case, the couple refused to carry out a prenatal diagnosis.

\section{Discussion and conclusions}

Thalassemia is the most common monogenic disease and it is a public health problem. Prevention and control of thalassemia require simple, rapid, and accurate screening tests, especially for couples that are at risk of conceiving children affected by severe thalassemia. In these cases, the molecular diagnosis is the only tool to recognize it. For this reason, the molecular diagnostic study is necessary to be certain of the diagnosis. The identification of these forms places relevant clinical implications for the prenatal diagnosis approach. Hence, a correct identification of the asymptomatic carrier is essential, including the in-depth follow-up analysis on the asymptomatic carrier's partner. The relevance of a detailed analysis of the hematological parameters and a precise information about the clinical implications linked to the thalassemia complications need to be highlighted as well. As to the latter, the molecular study of the genetic defect led to the identification of at-risk couples for thalassemia. Moreover, it allowed providing better, more comprehensive information about the risk of conceiving a child with thalassemia. In the case of asymptomatic carriers' couples taking the decision to have children, the following options are available: first, to be aware of the risks and facing the possibility to have a child affected by thalassemia; second, to avoid the biological conception of children; third, to take the decision to conceive own children, while opting for prenatal diagnosis to understand the genetic constitution of the fetus.

Currently, in the Basilicata region (Southern Italy), an extensive program of health education has been deployed, for both the health professionals and for the general public, aiming at providing the necessary information about the geographical risk, clinical course, modes of transmission and screening methods available of Thalassemia. The carrier screening in this case is of primary importance, and the identification of carriers' couples allows providing correct information for family planning to at-risk couples. The analysis of mutations of both carrier partners allows, through prenatal molecular diagnosis, to understand the genetic features of the fetus.

This paper has highlighted that the biochemical diagnosis alone, in some cases, is not sufficiently reliable to highlight the carriers of thalassemia trait.

The molecular analysis of the globin genes provides the most effective way to detect with certainty carriers of thalassemia trait. The detected mutations in this work can be identified with a simple and inexpensive kit. This means, in economic terms, a significant savings for health spending.

\section{Declaration of interest}

The authors report no conflicts of interest.

\section{Acknowledgments}

The authors thank "Association Gian Franco Lupo - Un Sorriso Alla Vita" (ONLUS: no-profit organization of social utility).

\section{References}

[1] Thein SL. Genetic modifiers of $\beta$-thalassemia. Haematologica. 2005; 90: 649-660. PMid:15921380 
[2] Kan YW, Chang JC. Molecular diagnosis of hemoglobinopathies and thalassemia. Prenat Diagn. 2010 Jul 30:608-10. PMid:20572100 http://dx.doi.org/10.1002/pd.2479

[3] Myers RM, Tilly K, Maniatis T. Fine structure genetic analysis of a beta-globin promoter. Science 1986; 232:613-618. PMid:3457470 http://dx.doi.org/10.1126/science.3457470

[4] Mosca A, Paleari R, Ivaldi G, Galanello R, Giordano PC. The role of haemoglobin A2 testing in the diagnosis of thalassaemias and related haemoglobinopathies. J Clin.Pathol.2009 Jan; 62(1): 13-7. PMid:19103851 http://dx.doi.org/10.1136/jcp.2008.056945

[5] Dell'Edera D, Malvasi A, Tinelli A, Mazzone E, Leo M, Monti V, Epifania AA. Importance of the molecular diagnosis in the screening of alpha-thalassemia. Recenti Prog Med. 2011 Jul-Aug; 102(7-8): 302-6. PMid:21779123

[6] Dell'Edera D, Pacella E, Epifania AA, Benedetto M, Tinelli A, Mazzone E, Laterza F, Malvasi A. Importance of molecular biology in the characterization of $\beta$-thalassemia carriers. Eur Rev Med Pharmacol Sci. 2011 Jan; 15(1): 79-86. PMid:21381502

[7] Dell'Edera D, Epifania AA, Malvasi A, Pacella E, Tinelli A, Capalbo A, Lioi MB, Di Renzo G. Incidence of $\beta$-thalassemia carrier on 1495 couples in preconceptional period. J Matern Fetal Neonatal Med. 2013 Mar; 26(5): 445-8. PMid:23039078 http://dx.doi.org/10.3109/14767058.2012.735998

[8] Kalleas C, Tentes I, Margaritis D, Anagnostopoulos K, Toli A, Pendilas D, Bourikas G, Tsatalas C, Kortsaris AH. Effect of HbS in the determination of $\mathrm{HbA}$ (2) with the TOSOH HLC-723G7 analyzer and the HELENA Beta-Thal Quik column kit. Biochem. 2007; 40: 242-247.

[9] Moosavi SF, Amirian A, Zarbakhsh B, Kordafshari A, Mirzahoseini H, Zeinali S, Karimipoor M. The carrier frequency of $\alpha$-globin gene triplication in an Iranian population with normal or borderline hematological parameters. Hemoglobin. 2011; 35(4):323-30. Thein SL. Genetic modifiers of $\beta$-thalassemia. Haematologica. 2005; 90: 649-660.

[10] Camaschella C, Kattamis AC, Petroni D, Roetto A, Sivera P, Sbaiz L, Cohen A, Ohene-Frempong K, Trifillis P, Surrey S, Fortina P. Different hematological phenotypes caused by the interaction of triplicated alpha-globin genes and heterozygous beta-thalassemia. Am J Hematol. 1997 Jun; 55(2):83-8. http://dx.doi.org/10.1002/(SICI)1096-8652(199706)55:2<83::AID-AJH6>3.0.CO;2-Z

[11] de Andrade TG, Fattori A, Saad ST, Sonati MF, Costa FF. Molecular identification of Sicilian ( $\delta \beta)$-thalassemia associated with beta-thalassemia and hemoglobin S in Brazil. Braz J Med Biol Res. 2002 Aug; 35(8): 873-6. PMid:12185378 http://dx.doi.org/10.1590/S0100-879X2002000800003

[12] Mosca A, Paleari R, Leone D, Ivaldi G. The relevance of hemoglobin F measurement in the diagnosis of thalassemias and related hemoglobinopathies. Biochem. 2009; 1797-1801. PMid:19580798 